\title{
CHARACTERIZATION OF THE RESTRICTED TYPE SPACES $R(X)$
}

\section{JAVIER SORIA AND PEDRO TRADACETE}

Abstract. We study functorial properties of the spaces $R(X)$, which have been recently introduced as a central tool in the analysis of the Hardy operator minus the identity on decreasing functions. In particular, we provide conditions on a minimal Lorentz space $\Lambda_{\varphi}$ so that the equation $R(X)=\Lambda_{\varphi}$ has a solution within the category of rearrangement invariant (r.i.) spaces. Moreover, we show that if $R(X)=\Lambda_{\varphi}$, then we can always take $X$ to be the minimal r.i. Banach range space for the Hardy operator defined in $\Lambda_{\varphi}$.

Mathematics subject classification (2010): 26D10, 46E30.

Keywords and phrases: Rearrangement invariant spaces, Lorentz spaces, restricted type, Hardy operator, optimal range.

\section{REFERENCES}

[1] M. A. ARIÑo AND B. MuCKenhoupt, Maximal functions on classical Lorentz spaces and Hardy's inequality with weights for nonincreasing functions, Trans. Amer. Math. Soc. 320 (1990), 727-735.

[2] C. Bennett And R. Sharpley, Interpolation of Operators, Pure and Applied Mathematics 129, Academic Press, 1988.

[3] S. BOZA AND J. SORIA, Solution to a conjecture on the norm of the Hardy operator minus the identity, J. Funct. Anal. 260 (2011), no. 4, 1020-1028.

[4] Y. A. BRUdNyI AND N. Y. KRUglyak, Interpolation Functors and Interpolation Spaces. Volume I, North-Holland, 1991.

[5] M. J. CARRo AND J. Martín, A useful estimate for the decreasing rearrangement of the sum of functions, Q. J. Math. 55 (2004), no. 1, 41-45.

[6] M. J. Carro, L. Pick, J. Soria, And V. Stepanov, On embeddings between classical Lorentz spaces, Math. Ineq. Appl. 4 (2001), 397-428.

[7] O. Delgado AND J. Soria, Optimal domain for the Hardy operator, J. Funct. Anal. 244 (2007), no. $1,119-133$.

[8] D. E. Edmunds, R. KeRMAN, AND L. Pick, Optimal Sobolev imbeddings involving rearrangementinvariant quasinorms, J. Funct. Anal. 170 (2000), no. 2, 307-355.

[9] N. J. Kalton, N. T. Peck, And J. W. Roberts, An F -Space Sampler, London Math. Soc. Lecture Notes 89, Cambridge University Press, 1984.

[10] S. G. Krein, Yu. I. Petunin, And E. M. Semenov, Interpolation of Linear Operators, Amer. Math. Soc., 1982.

[11] N. Y. Kruglyak, L. Maligranda, And L. E. Persson, A Carlson type inequality with blocks and interpolation, Studia Math. 104 (1993), no. 2, 161-180.

[12] A. NeKVINDA AND L. PICK, Optimal estimates for the Hardy averaging operator, Math. Nachr. 283 (2010), no. 2, 262-271.

[13] A. NeKVinda AND L. Pick, Duals of optimal spaces for the Hardy averaging operator, Z. Anal. Anwend. 30 (2011), 435-456.

[14] S. OKada, W. J. Ricker, And E. A. SÁnchez-PÉReZ, Optimal Domain and Integral Extension of Operators Acting in Function Spaces, Operator Theory: Advances and Applications, vol. 180, Birkhäuser Verlag, 2008.

[15] S. RodrigueZ-López and J. Soria, A new class of restricted type spaces, Proc. Edinb. Math. Soc. 54 (2011), 749-759. 
[16] T. Shimogaki, A note on norms of compression operators on function spaces, Proc. Japan Acad. 46 (1970), 239-242.

[17] J. SoRIA, Lorentz spaces of weak-type, Quart. J. Math. Oxford Ser. (2) 49 (1998), 93-103.

[18] J. SORIA, Optimal bounds of restricted type for the Hardy operator minus the identity on the cone of radially decreasing functions, Studia Math. 197 (2010), 69-79. 